\title{
APLICAÇÃO DE CARTAS DE CONTROLE NO PROCESSO DE FABRICAÇÃO DE PISOS SÓLIDOS DE TAUARI (Couratari oblongifolia)
}

\author{
Edith Mara Christino ${ }^{1}$, Ghislaine Miranda Bonduelle ${ }^{2}$, Setsuo Iwakiri ${ }^{3}$
}

(recebido: 11 de novembro de 2008; aceito: 30 de abril de 2010)

\begin{abstract}
RESUMO: As atividades básicas de controle da qualidade na fábrica estão nas repetições de análise e melhorias, para reduzir as variações de qualidade. Faz-se necessário então determinar a magnitude das variações atuais e prosseguir com os fatores que as causam. No controle de qualidade, faz-se a análise, pesquisa e prevenção da ocorrência de defeitos, minimizando o prejuízo ou, melhor ainda, evitando que isto aconteça. Este trabalho analisou, por meio de cartas de controle de variáveis, a qualidade de produção do setor de moldureiras, no processo de fabricação de pisos de tauari (Couratari oblongifolia Ducke \& R. Knuth). Foram coletadas vinte e sete amostras de tamanho um. As variáveis avaliadas foram: largura, espessura e comprimento do macho, espessura e profundidade da fêmea, além da largura e espessura do piso. Os resultados demonstraram que todas as variáveis apresentaram-se fora de controle estatístico de qualidade. Entre as variáveis avaliadas, a espessura da fêmea apresentou a maior variabilidade do processo, em razão da alta contração da madeira dessa espécie, tendo como consequência a necessidade de produção da fêmea com maior espessura que a especificação, em razão da adsorção de umidade durante o processo e assegurar que ocorra encaixe perfeito do macho e fêmea.
\end{abstract}

Palavras-chave: Controle de qualidade, pisos em madeira tropical, qualidade de produção.

\section{APPLICATION OF CONTROL CHARTS IN THE PRODUCTION PROCESS OF TAUARI (Couratari oblongifolia) WOOD FLOORING}

\begin{abstract}
The basic quality control activities at the factory are the repetitive analysis and improvements to reduce the variations of quality. Then, it is necessary to determinate the magnitude of the current variations and to identify and analyze the factors that cause them. In quality control the occurrence of flaws is analyzed, researched and prevented, minimizing, then, the damage or, even better, avoiding it to happen. This work analyzed through control charts for variables, the quality of the production of the molders in manufacturing Tauari (Couratari oblongifolia Ducke \& R. Knuth) hardwood floors. Twenty-seven samples size one were collected. The variables considered were male's width, thickness and length, goove thickness and depth, besides the width and thickness of the floor. The results have showed that all the variables were out of the statistic quality control. Among the variables considered, groove thickness presented the greater process variability due to the high shrinkage of the species. As a result, there is a need to the production of a groove thickness bigger than the specification to assure a perfect fit, due to the moisture absorption during the process.
\end{abstract}

Key words: Quality control, hardwood floors, quality of the production.

\section{INTRODUÇÃO}

Os pisos de madeira fabricados no Brasil são classificados como laminados ou sólidos. De acordo com o Projeto de Norma 31.000.13-0001 da ABNT/CB31 (ASSOCIAÇÃO BRASILEIRA DE NORMAS TÉCNICAS ABNT, 2009), de abril de 2009, assoalho ou "pisos sólidos" é uma peça de encaixe macho/fêmea em 2 ou 4 lados. No acabamento, são utilizadas várias camadas de verniz com uretano acrílico e selador com óxido de alumínio que conferem ao produto alta resistência à abrasão e diferentes intensidades de brilho. Na produção de pisos sólidos são empregadas espécies de madeiras tropicais consideradas nobres, pelas suas características estéticas, de resistência e de durabilidade (IWAKIRI et al., 2006). O volume de produção de pisos sólidos, em 2005, foi de 12,8 milhões de $\mathrm{m}^{2}$, sendo que, deste total, quase $75 \%$ foi destinado para exportações, o que demonstra no mercado internacional a grande preferência e valorização de pisos sólidos produzidos com madeiras tropicais nobres (ASSOCIAÇÃO BRASILEIRA DA INDÚSTRIA DA MADEIRA PROCESSADA MECANICAMENTE - ABIMCI, 2006).

A tríade preço, qualidade e consumidor é a base da competitividade e tem levado muitas empresas a repensarem seus conceitos para sobreviverem no mercado.

Não é nova a tendência de quantificar a capacidade de um processo e de padronizar os métodos, ferramentas e terminologia. Cada vez mais aceita-se a idéia de que as

\footnotetext{
${ }^{1}$ Engenheira Industrial Madeireira - Universidade Federal do Paraná - Av. Lothário Meissner, 632 - Jardim Botânico - 80210 -170 Curitiba, PR - emchristino@yahoo.com.br

${ }^{2}$ Engenheira Florestal, Professora Dra. em Engenharia Florestal - Departamento de Engenharia e Tecnologia Florestal/DETF Universidade Federal do Paraná/UFPR - Av. Lothário Meissner, 632 - Jardim Botânico - 80210-170 - Curitiba, PR - ghislaine@ ufpr.br ${ }^{3}$ Engenheiro Florestal, Professor Dr. em Engenharia Florestal - Departamento de Engenharia e Tecnologia Florestal/DETF - Universidade Federal do Paraná/UFPR - Av. Lothário Meissner, 632 - Jardim Botânico - 80210-170 - Curitiba, PR - setsuo@ufpr.br
}

Cerne, Lavras, v. 16, n. 3, p. 299-304, jul./set. 2010 
empresas que estimam capacidade do processo durante o planejamento de qualidade, terão melhores desempenhos em comparação àquelas que não a empregam. Juran \& Gryna (1991) já afirmavam que o planejamento da qualidade tem seu principal efeito nos custos, pois, geralmente maior qualidade leva a um processo de menor custo a longo prazo.

Com o planejamento da qualidade, eliminam-se ações improvisadas, decisões com base intuitiva e subjetivismo. Mas, tem-se a crença de que qualidade mais alta custa mais. Apesar de o melhoramento da qualidade ter um custo, a sua finalidade é de criar e manter uma empresa saudável, crescente e lucrativa com empregos estáveis (BONDUELLE, 2007).

Em decorrência da expansão comercial, a tecnologia foi aumentando, e ferramentas e conceitos foram inventados para o gerenciamento da qualidade. Esses novos conceitos consideram que as atividades básicas de controle da qualidade, na fábrica, estão nas repetições de análise e melhorias, para reduzir as variações de qualidade (KUME, 1993).

Entre as ferramentas mais utilizadas no controle de processos estão as Cartas de Controle que são gráficos de análise e monitoramento de um processo em função do tempo, por meio de duas características básicas: sua centralização e sua dispersão. A centralização pode ser verificada pela média do processo e a dispersão estimada pelo desvio-padrão ou amplitude dos dados.

Existem dois tipos básicos de cartas de controle: por variáveis e por atributos (BONDUELLE, 2006; CAMPOS, 1994; WERKEMA, 1995).

- Cartas de controle por variáveis: são baseadas nas distribuições contínuas e apresentam dados que podem ser medidos ou que sofrem variações contínuas. Exemplos: variações na altura de um talhão, resistência à tração.

- Cartas de controle por atributos: são baseadas em distribuições discretas e possuem um caráter dicotômico, ou seja, os dados só podem ser contados ou classificados. Exemplos: passa/não passa; mole/duro; conforme/nãoconforme.

Conduziu-se este trabalho, com o objetivo de monitorar e analisar por meio da aplicação de cartas de controle de variáveis, a qualidade de produção do setor das moldureiras, no processo de fabricação de pisos de madeira maciça de tauari (Couratari oblongifolia Ducke \& R. Knuth).

\section{MATERIAL E MÉTODOS}

\subsection{Material}

A empresa, objeto deste estudo, está localizada no município de Curitiba, Estado do Paraná, e trabalha com várias espécies tropicais na produção de pisos de madeira destinados à exportação. Neste trabalho, foi estudada a espécie Tauari (Couratari oblongifolia Ducke \& $R$. Knuth), em razão da disponibilidade de um maior número de amostras a serem analisadas. A avaliação da qualidade foi realizada no setor de usinagem com moldureiras.

O piso sólido acabado tem como especificações:

- Largura: 90,0 mm

- Espessura: $15 \mathrm{~mm}$

- Comprimento: variável de 300 a 2.100 pés.

\subsection{Coleta de dados}

As variáveis avaliadas foram: altura, espessura e comprimento do macho; espessura e profundidade da fêmea; além da largura e espessura do piso.

No total, foram coletadas vinte e sete amostras, sendo que cada amostra foi considerada como de tamanho um, ou seja, cada peça foi considerada como uma amostra, não havendo amostras com repetições. Em controle estatístico de processos, denomina-se o número de repetições da amostra como tamanho de amostra.

Os dados foram extraídos de uma planilha elaborada pelo controle de qualidade da empresa, na qual eram anotadas as medições que foram realizadas com paquímetros, conforme ilustradas na Figura 1.

\subsection{Construção das cartas de controle}

Para cada variável, os dados foram colocados em um gráfico comparando-se com as especificações. Neste trabalho, são apresentados gráficos para as seguintes variáveis de controle: espessura, comprimento e altura do macho; largura do piso; a profundidade e a espessura da fêmea, sendo que para este último, contendo os Limites Superior e Inferior, além das Médias de Controle. Os Limites de Controle para a Média, foram calculados com base nas fórmulas apresentadas por Paladini (1990) a seguir:

$\mathrm{LSC}=\mathrm{X}+\mathrm{E} 2 * \mathrm{R}$
$\mathrm{LIC}=\mathrm{X}-\mathrm{E} 2 * \mathrm{R}$

Em que:

LSC $=$ Limite Superior de Controle para Médias

LIC $=$ Limite Inferior de Controle para Médias

$\mathrm{R}=$ Amplitude móvel média

$\mathrm{X}=$ Média do processo

E2 =Valor tabelado em função do tamanho da amostra (n);

Para amostras individuais $\rightarrow$ E2 $=2,66^{*}$

*Valor retirado de tabela da ASTM-STP 15D reproduzida pela American Society for Quality Control Statistics Division - ASQC (1983, p. 133). 

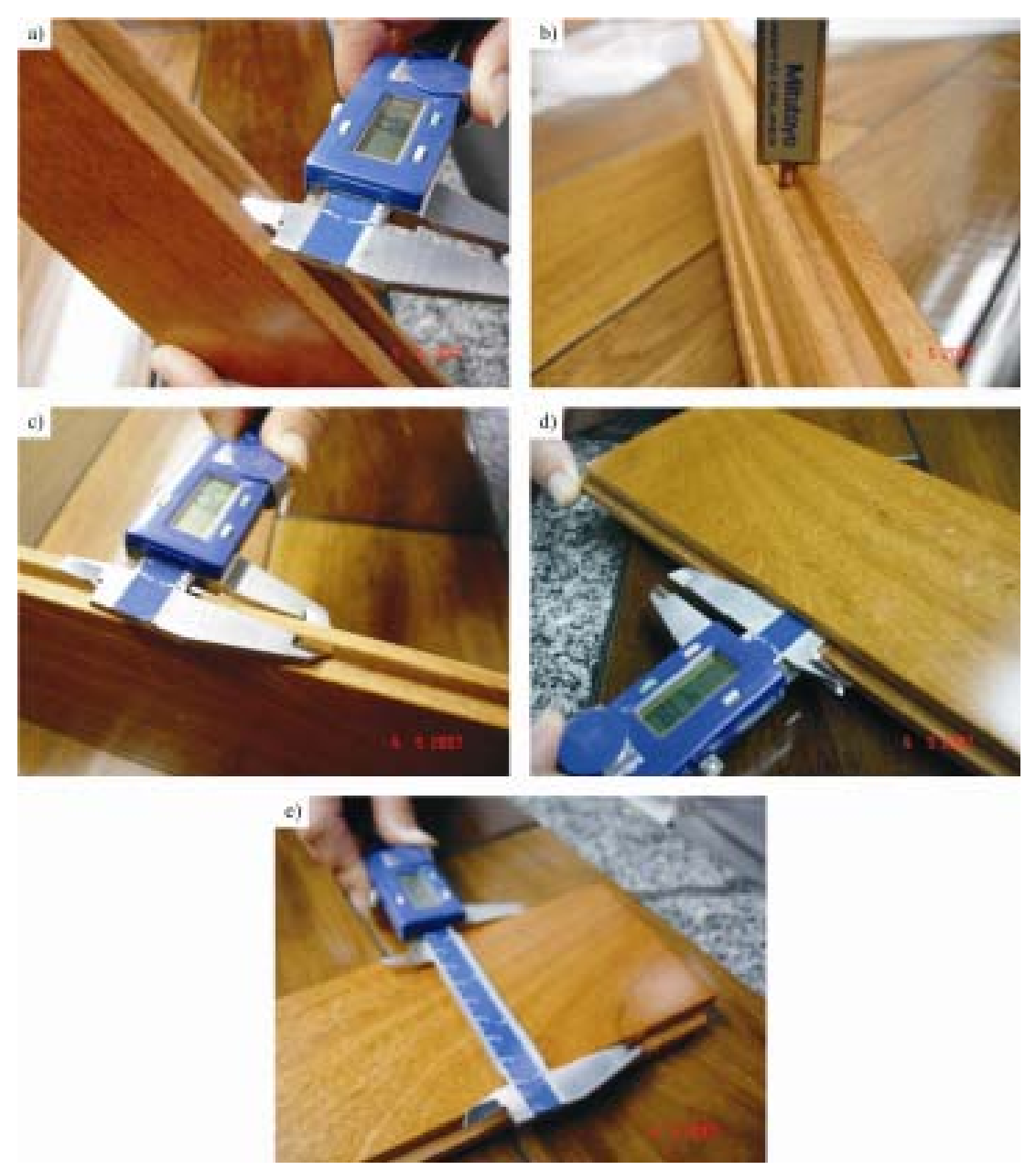

Figura 1 - Medições realizadas nos pisos: a) Espessura da fêmea; b) Profundidade da fêmea; c) Espessura do macho; d) Comprimento do macho; e) Largura do piso.

Figure1 - Measurements done in the floors: a) Groove thickness; b) Groove depth; c) Tongue thickness; d) Tongue length; e) Floor width.

Após a construção dos gráficos, foi realizada a interpretação dos mesmos pelos seguintes critérios apresentados por Bonduelle (2006):

(a) Enquanto os pontos nos gráficos se distribuem aleatoriamente em torno da Linha Média (LM) não se deve interferir no processo, pois significa que o processo está sujeito somente à ação de causas aleatórias, ou seja, está sob controle.

(b) Se além das causas aleatórias, estão presentes causas especiais, então o processo está fora de controle e são as seguintes evidências desse fato:

- Um ponto acima do LSC ou abaixo do LIC é interpretado como sinal de que o processo deve estar fora de controle e alguma ação corretiva é necessária;
- Tendências (7 ou mais pontos) ascendentes ou descendentes;

- Variabilidade extrema ou mínima;

- Sequências (7 ou mais pontos) acima ou abaixo da Linha Média;

- Ciclos.

\subsection{Análise das causas e sugestões de ações corretivas}

Para a análise das causas da variabilidade do processo, foi utilizado o método de análise de falhas (também conhecido como método dos "Porquês"). Esse método consiste em efetuar uma pergunta e da resposta obtida, tornar a efetuar uma nova pergunta. As estatísticas demonstram que na quinta ou sexta pergunta

Cerne, Lavras, v. 16, n. 3, p. 299-304, jul./set. 2010 
chega-se a causa fundamental do problema (BONDUELLE, 2006).

Após a análise das causas da variabilidade, foram sugeridas ações corretivas para solução dos problemas constatados na linha de produção.

\section{RESULTADOS E DISCUSSÃO}

\subsection{Cartas de controle para estabilidade do processo}

A análise do processo foi realizada para estabelecer alguns procedimentos e mudanças visando a sua melhoria.

Analisando-se os gráficos da moldureira $2 \mathrm{em}$ relação aos limites de especificação, verifica-se que o
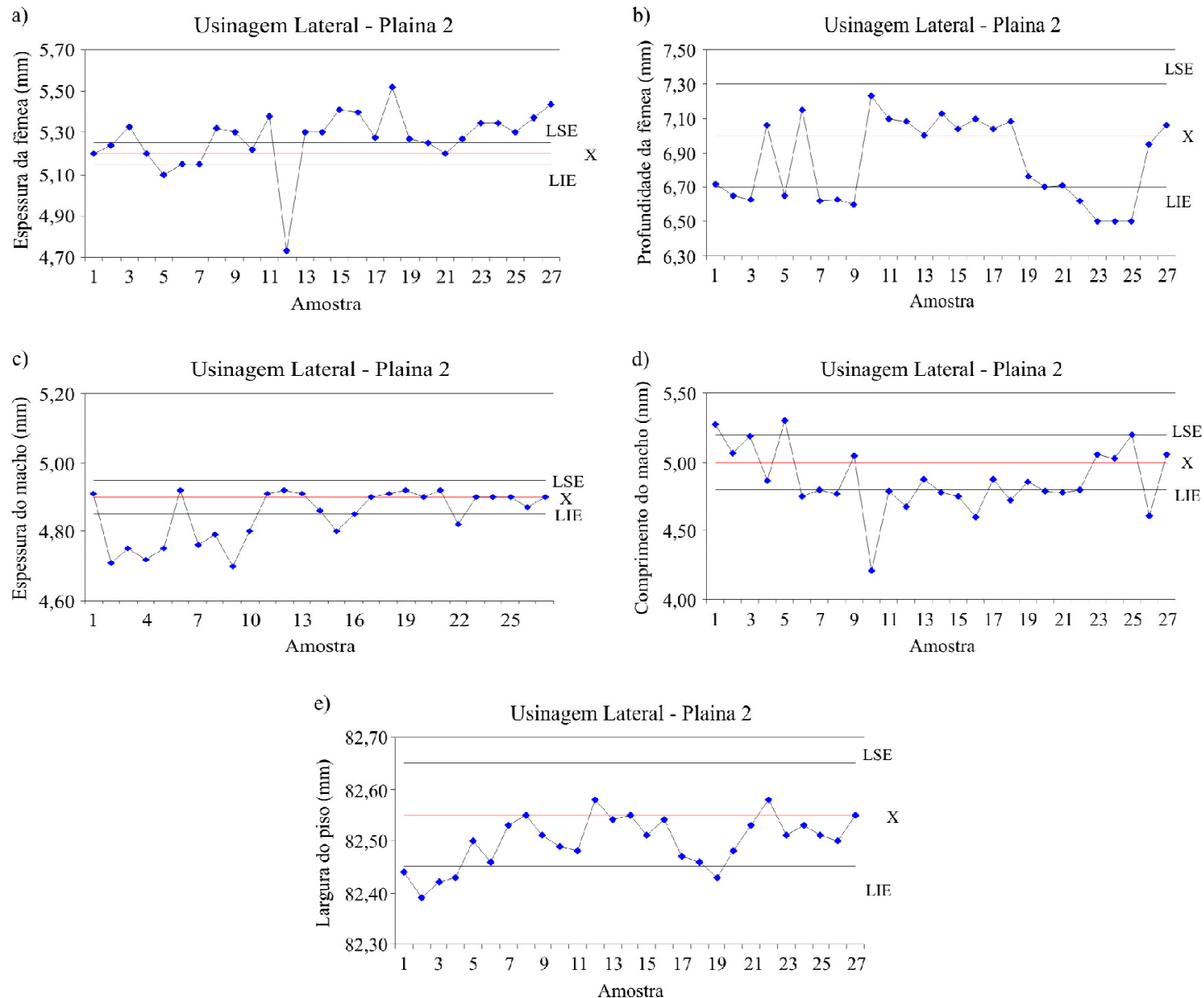

LSE: limite superior de especificação; LIE: Limite inferior de especificação; X= média do processo.

Figura 2 - Gráfico de controle das variáveis analisadas: a) Espessura da fêmea; b) Profundidade da fêmea; c) Espessura do macho; d) Comprimento do macho; e) Largura do piso.

Figure 2 - Control chart of analyzed variables: a) Groove thickness; b) Groove depth; c) Tongue thickness; d) Tongue length; e) Floor width.

Cerne, Lavras, v. 16, n. 3, p. 299-304, jul./set. 2010 
Analisando detalhadamente a Figura $2 \mathrm{~b}-$ profundidade da fêmea, observa-se que o processo está fora de controle estatístico com amostras abaixo do limite inferior de especificação e apresentando tendência descendente a partir do ponto 9 até o ponto 23, com profundidades de $7,25 \mathrm{~mm}$ e $6,40 \mathrm{~mm}$, respectivamente. Podese observar também, um forte deslocamento do processo em direção ao limite de especificação inferior. Portanto, além de disperso, o processo está descentralizado.

De todas as variáveis analisadas no trabalho, a que sofreu maior dispersão foi a espessura da fêmea. Por este motivo, foi construída para esta variável a carta de controle completa com os limites de controle e de especificação.

\subsection{Carta de controle para a variável espessura da fêmea}

Na Figura 3, encontram-se ilustradas as variações da espessura da fêmea no processo de usinagem lateral com respectivos limites de especificações e de controle.

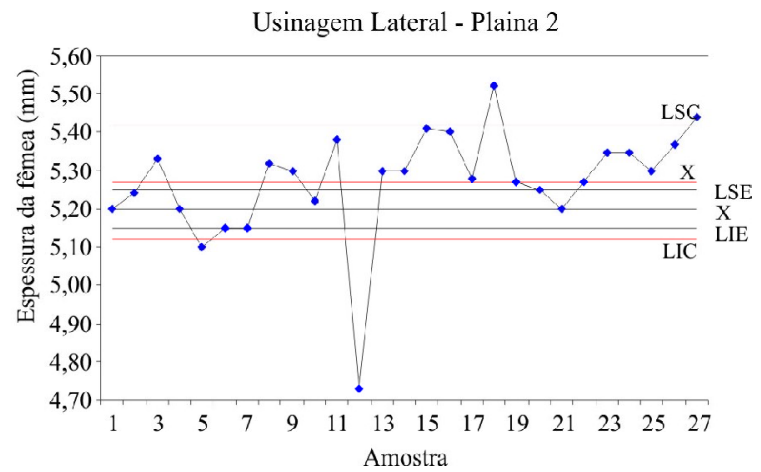

LSE: limite superior de especificação; LIE: limite inferior de especificação; $\mathrm{X}=$ média do processo; $\mathrm{LSC}=$ limite superior de controle; $\mathrm{LIC}=$ limite inferior de controle.

Figura 3 - Variações da espessura da fêmea.

Figure 3 - Variations of groove thickness.

Os limites de controle que são estabelecidos pela média e dispersão dos dados (amplitude) indicam que o processo não é capaz de atender às especificações, pois, existem pontos fora dos limites de controle e dos limites de especificações, com tendências de pontos ascendentes e descendentes, como pode ser constatado para as amostras 18 e 12, respectivamente. O processo demonstra estar extremamente disperso, com os limites de especificação entre a média do processo e o limite inferior de controle, além do processo estar completamente deslocado acima do limite superior de especificação.

\subsection{Análise de causas da variabilidade e proposta de ações corretivas}

Utilizando o método dos "porquês", foram detectadas três possíveis causas de ocorrências de variações na espessura da fêmea, as quais são descritas a seguir:

Causa 1:

Espécies de maior massa específica apresentam maior contração, como é o caso do Tauari. Mesmo que matematicamente a contração esteja dentro de limites que assegurem o perfeito encaixe macho-fêmea, é preciso considerar que empenamentos, torções possam acontecer $\mathrm{e}$, consequentemente, surgirem problemas no encaixe. Controlar rigorosamente a umidade de equilíbrio das peças para evitar variações dimensionais após o encaixe machofêmea. Se a espécie possuir grã irregular, por exemplo com inclinação superior a $15 \%$, será propensa a empenamentos, então a direção de corte deverá ser considerada. Realizar o corte paralelo à casca e não ao eixo da árvore poderá reduzir o empenamento das peças.

Ação corretiva proposta: as especificações devem ser reavaliadas, uma vez que a umidade é um fator importante no processo e está diretamente relacionada com a contração da madeira. É importante considerar que a madeira com maior teor de umidade que o especificado, antes da usinagem, resultará em menor espessura da fêmea, após a estabilização, em razão da perda de umidade e contrações pós-usinagem. Na situação inversa, madeira seca abaixo do teor de umidade especificado, resultará em maior espessura da fêmea após a estabilização.

Causa 2:

A falta de padronização na execução dos métodos de medição e coleta de dados. Uma vez que a empresa adotou um sistema de rodízio, ou seja, várias pessoas do controle de qualidade avaliam o processo durante todo o dia, portanto, pode ter havido falha humana na medição.

Ação corretiva proposta: Realizar treinamento e a capacitação do pessoal do controle de qualidade responsável pelas medições. Esse treinamento deve ser tanto teórico quanto prático e envolver aspectos de motivação e conscientização para a importância da qualidade. Deverá ser avaliada a eficácia do treinamento.

Causa 3:

A inexistência do monitoramento de processos não permite a coleta de dados para analise e implantação de ações corretivas.

Cerne, Lavras, v. 16, n. 3, p. 299-304, jul./set. 2010 
Ação corretiva proposta: Elaborar gráficos de todas as espécies produzidas no dia, pois a visualização gráfica das variáveis facilita a análise dos funcionários envolvidos no processo, permitindo uma visão mais ampla de todo o funcionamento da produção. Os gráficos também são úteis ao comunicar os resultados a líderes, provedores, clientes, e outros que têm interesse na melhoria da qualidade. Sendo os dados, a base para tomada de decisões confiáveis durante a análise de um problema e como toda obtenção de dados deve ser seguido por algum tipo de ação, é importante uma coleta confiável, já que essas indicarão as características das variáveis durante o processo. Por sua vez, na coleta de dados se fazem necessários alguns cuidados, entre eles: a precisão dos instrumentos, as normas de medições observadas e padronizadas, a pessoa encarregada da coleta que deverá ser treinada anteriormente.

\section{CONCLUSÕES}

As cartas de controle demonstraram que o processo não é capaz de atender às especificações do produto, pois foi constatada a variabilidade no processo para todos os fatores analisados no setor de moldureiras na etapa de usinagem da madeira para fabricação de pisos maciços de Tauari (Couratari oblongifolia Ducke \& R. Knuth).

A variável que sofreu maior dispersão foi a espessura da fêmea, recomendando-se um controle mais rigoroso da umidade das peças e desdobro paralelo à casca em vez de paralelos ao eixo da árvore e assegurar para que haja um encaixe perfeito com o macho.

Foi identificada a necessidade de trabalhar de forma planejada, bem definida e de modo a otimizar o uso dos recursos para a redução de custos tanto pela eliminação de desperdício, que requerem correções, quanto pela necessidade de alterar decisões que se mostram equivocadas.

A implementação das ações corretivas de controle de qualidade permitirá que a empresa reduza a frequência de erros, do retrabalho, das falhas de produção, insatisfação dos clientes e também aumente o rendimento, a capacidade e o desempenho de entrega.

Cerne, Lavras, v. 16, n. 3, p. 299-304, jul./set. 2010

\section{REFERÊNCIAS BIBLIOGRÁFICAS}

AMERICAN SOCIETY FOR QUALITY CONTROL STATISTICS DIVISION. Glossary and tables for statistical quality control. Wisconsin, 1983. 185 p.

ASSOCIAÇÃO BRASILEIRA DA INDÚSTRIA DA MADEIRA PROCESSADA MECANICAMENTE. Estudo setorial 2006. Curitiba, 2007. $51 \mathrm{p}$.

ASSOCIAÇÃO BRASILEIRA DE NORMAS TÉCNICAS. CB31: pisos de madeira: terminologia, projeto 31.0003-001 de abril de 2009. Rio de Janeiro, 2009. 18 p.

BONDUELLE, G. M. Gerenciamento da qualidade. Curitiba: UFPR, 2007. Notas de Aula.

BONDUELLE, G. M. Gestão da qualidade total para a produção florestal. Curitiba: UFPR_PECCA, 2006. 205 p. Apostila.

CAMPOS, V. F. TQC: controle de qualidade total: no estilo japonês. 5. ed. Belo Horizonte: Fundação Christiano Ottani, 1994.

IWAKIRI, S.; STINGHEN, A. B. M.; NUNES, E. L. S.; ZAMARIAN, E. H. C.; ADRIAZOLA, M. K. O. Utilização de lâminas de Eucalyptus grandis e Eucalyptus maculata como alternativas para produção de piso laminado com montagem direta. Floresta, Curitiba, v. 36, n. 3, p. 425-430, 2006.

JURAN, J. M.; GRYNA, F. M. Controle de qualidade. São Paulo: Makron Books, 1991. 360 p.

KUME, H. Métodos estatísticos para a melhoria da qualidade. São Paulo: Gente, 1993. 148 p.

PALADINI, E. P. Controle de qualidade: uma abordagem abrangente. São Paulo: Atlas, 1990. 155 p.

WERKEMA, M. C. C. Ferramentas estatísticas básicas para o gerenciamento de processos. Belo Horizonte: Fundação Christiano Ottoni, 1995. v. 2, 284 p. 